\title{
Cross-Cultural Adaptation of the Vancouver Scar Scale - Baryza Version to Brazilian Portuguese
}

\author{
Costa PTL ${ }^{1 *}$, Echevarría-Guanilo $\mathrm{ME}^{1}$, Gonçalves $\mathrm{N}^{1}$, Gonçalves $\mathrm{AC}^{2}$ and \\ Turgeon $\mathrm{L}^{3}$ \\ ${ }^{1}$ Departament of Nursing, Universidade Federal de Santa Catarina, Brazil \\ ${ }^{2}$ Department of Physical Therapy, Centro Universitário Barão de Mauá de Ribeirão Preto, Brazil \\ ${ }^{3}$ Department of Therapeutic Services, Shriners Hospital for Children, United States
}

\section{Research Article}

Volume 4 Issue 1

Received Date: January 31, 2020

Published Date: February 20, 2020

DOI: $10.23880 /$ nhij-16000217

*Corresponding author: Pollyana Thays Lameira da Costa, Department of Nursing, Federal University of Santa Catarina, Block I (CEPETEC) - Health Sciences Center - Ground Floor, 88040-900, Florianópolis /SC, Brazil, Tel: +55 483721 3433; Email: pollyana. lameira@gmail.com

\section{Abstract}

Objective: To perform the cross-cultural adaptation of the Vancouver Scar Scale - Baryza Version to the Brazilian population with burns.

Method: Methodological study carried out in seven steps: 1) translation of the original scale into two versions; 2) summary of translations; 3) evaluation by expert committee; 4) back translation in two versions; 5) summary of back translations; 6) comparison with the original scale; and 7) semantic validation. The 18 participants were invited by email based on strict criteria determined for each stage.

Results: The steps culminated in an instrument which did not need any modifications according to the original author of the scale, which was then subjected to semantic analysis, which caused difficulties in translation especially in relation to the vascularization and pigmentation items, but the evaluators rated the overall impression as good and very important for the condition.

Conclusion: The preliminary version derived from the methodological pathway presents adequate semantic validity and the instrument proves to be suitable for future studies, pretesting and evaluation of its psychometric properties.

Keywords: Nursing evaluation; Scar; Methodological research in nursing; Burns; Techniques; measurements; Measurement equipment

\section{Introduction}

Scars caused by burn injuries are common in children and adults, resulting from widespread damage to skin tissue [1]. An imbalance between destruction and collagen deposition, induced by various factors during healing, leads to the development of pathological scarring [2]; the size and depth of the burn, as well as the time required for the injury to heal, will also influence this occurrence [1].

Scar tissue is noticeably different from healthy skin around it in color, pigmentation, vascularity, thickness and flexibility and also causes a multitude of signs and symptoms 
including pain, itching, erythema and dryness. If located near a joint, scar contracture can lead to joint stiffness and thus, besides causing aesthetic problems, can cause symptomatic, psychological and functional problems, causing a significant impact on quality of life [3].

Accurate scar assessment includes its evolution and management and is imperative for evaluating and comparing the effectiveness of clinical treatments between different patient groups $[4,5]$, which optimizes treatment [6] and may alleviate patient concerns about the healing prognosis [2] and thus improve their quality of life [6].

There is still no consensus regarding the best tool for scar assessment. An ideal assessment would perfectly describe the important features of the scar, as well as accurately documenting its evolution in response to treatment [7].

In this context, the Vancouver Scar Scale (VSS) was designed to evaluate the physical and aesthetic characteristics of scars and is probably the most popular scale evaluated by the observer. It includes four items, "vascularization", "pigmentation", "pliability" and "height", whose total sum ranges from 0 to 13 , the higher the score, the worse the scar [5].

After the development of VSS, about ten versions were published [8]. One of versions was by Baryza and Baryza [9], which, in order to improve the accuracy of the scale, added the subitem "mixed pigmentation", which refers to the heterogeneity of the amount of pigments in the same scar area evaluated [10], in addition to the introduction of a transparent plate used to evaluate the items "height", "pigmentation" and "vascularization" [9]; a tool that would support measurement standardization, i.e., it helps the assessment to become more objective.
Therefore, the cross-cultural adaptation of scales is an important issue, because if they are used in different countries, they must be translated into the local language, culturally adapted and proven valid [11]. The validation and adaptation of cross-cultural scales is also a way of standardizing instruments across populations [12].

Thus, the aim of this study was to perform the crosscultural adaptation of Baryza's version of the Vancouver Scar Scale for use in the Brazilian population with burns.

\section{Method}

This is a methodological research conducted between April 2017 and December 2018, with a proposal based on the methodology of Beaton, et al. [13] and adjustments as proposed by Ferrer, et al. [14], regarding the order of the "expert committee" and "back translation" steps and the inclusion of "semantic validation" before the pretest, suggested by Pasquali [15]. Such step order adjustments have already been adhered to in previous validation studies [16-20].

Thus, seven steps were selected for the methodological route, namely: 1) translation of the scale into the Portuguese language of Brazil in two versions; 2) summary of Portuguese translations; 3) evaluation by expert committee; 4) back translation in two versions; 5) summary of back translations; 6) Comparison with the original version; and 7) semantic validation.

There were 18 participants, with distinct collaborations in the aforementioned stages, who were mostly contacted by email, who participated voluntarily by signing the free and informed consent.

Thus, the following steps were performed (Figure 1):

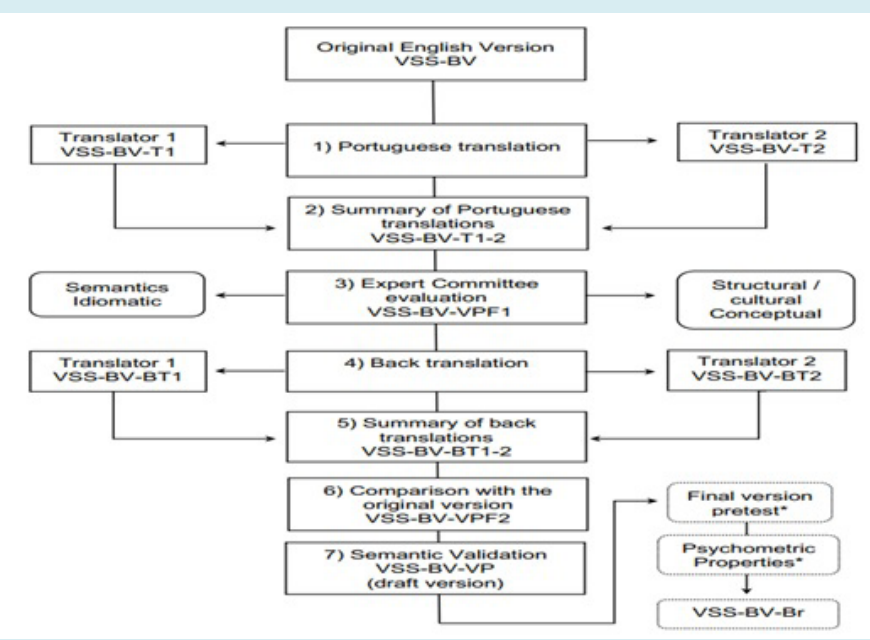

Figure 1: Steps performed for the cross-cultural adaptation of the instrument.

*Note: Steps to be followed in future studies. 


\section{Translation of the Scale Into Brazilian Portuguese in Two Versions}

The translation of the original language scale (English) to Portuguese was performed independently by two bilingual Brazilian translators. Both were sent a document containing a brief orientation on the organization of the content to be translated. One of the translators was informed about the objectives of the research, had a master's degree in oncology and a doctorate in radiation biology from an English university, and thus knew the technical health terms; The other was not informed about the objectives of the study, had a degree in the English language and had no relationship with the health area, therefore, without knowledge on the subject investigated. The resulting translations were named Vancouver Scar Scale - Baryza Version 1 (VSS-BV-T1) and Vancouver Scar Scale - Baryza Version 2 (VSS-BV-T2).

\section{Summary of Portuguese Translations}

The summary of the translations was obtained through joint consensus between the researchers and a mediator in the discussions about the differences between the translated versions. The person assigned to the role of mediator had training in physiotherapy and rehabilitation in burned people. For the formalization of this step, the researchers issued an invitation via e-mail for a videoconference meeting where the appropriate decisions regarding the two translations were made. This process resulted in the consensus called the Vancouver Scar Scale - Translation 1-2 (VSS-BV-T1-2).

\section{Evaluation by Expert Committee}

The committee of experts was attended by five health professionals with knowledge of the source language of the scale and who were involved with the area of burns to some degree: three nurses (one with expertise in the validation methodology, one with training and experience in the area of burns who in addition to working in the area of burns, had also suffered severe burns in childhood), a physiotherapist (working in intensive care, and surgical clinic and burns outpatient clinic) and a doctor (responsible for a research group on wound prevention and treatment).

The members of the committee were sent an email which contained the objectives of the study and the current step, together with an instrument for evaluating the equivalence between the original and translated versions (consensually), which aimed to evaluate the title, items and sub-items based on the evaluator's agreement with respect to the objectivity, clarity and relevance of the scale components using four answer options: agree, partially agree, partially disagree and disagree. Participants were also asked to justify their answers. The report produced by each participant from the evaluation of the three previous VSS-BV documents (T1, T2 and T1-2) resulted in the Pre-Final Version 1 (VSS-BV-VPF1), which was consolidated by the researchers.

\section{Back Translation in Two Versions}

The VSS-BV-VPF1 version was translated into English by two other bilingual translators, unrelated to health and native to the source language of the scale. They were contacted via email and advised not to consult the original version of the scale and were not informed about the objectives and concepts involved. The resulting versions were titled Vancouver Scar Scale - Baryza Version - Back-Translation 1 (VSS-BV-BT1) and Vancouver Scar Scale - Baryza Version Back-Translation 2 (VSS-BV-BT2).

\section{Summary of Back Translations}

For the summary of the back-translations, the researchers and a person designated to act as mediator of the stage were gathered. The guest was fluent in English, a native of the target language (Brazilian Portuguese), nurse and an intensive care specialist. Consultations with other professionals, such as burn and vascular specialists, were considered for this step, if necessary, so that doubts regarding the translations of the terms could be clarified. The back translations and the original version were thoroughly analyzed and the resulting report containing all the issues addressed gave rise to the English version Vancouver Scar Scale - Baryza Version - BackTranslation 1-2 (VSS-BV-BT1-2).

\section{Comparison with the Original Version}

The next step consisted in comparing the last version produced with the original version, analyzed by the author / principal author of the original instrument. A file containing a table with the results of the completed steps was sent by email which highlighted the summary of the back translations and the original version. The resulting version of this internship was, in Portuguese; Vancouver Scar Scale Baryza Version - Versão Pré-final 2 (VSS-BV-VPF2).

\section{Semantic Validation}

The semantic validation step consisted of verifying the comprehension of the instrument components, the VSS-BVVPF2 version was analyzed by a group of four professionals (three nurses and one doctor), who, like all the other guest participants, did not participate in any other process step. In order to perform the semantic validation, the Specific Semantic Validation Sheet and the General Impression Form - both based on the DISABKIDS $®$ validated Portuguese instruments [21] - were used, as well as the instruction for the application of the translated scale and a piece of acrylic 
made for this purpose.

The semantic assessment instrument contained the prefinal version of the scale and questions about its relevance, difficulty of understanding, clarity and consistency of items and sub-items, how the evaluator could express them better and what they meant to them. In addition, the overall assessment instrument consisted of collecting the evaluators' opinion on the overall presentation of the scale, items, difficulty in answering the scale response categories, relevance of the items to the health/disease condition, and suggestions for scale modification and addition of other details.

The figure of the scale and explanations about its dimensions and use of each area were inserted in the instructions. In addition, it was attempted to present the expected answers and synonyms that might be more familiar to the evaluators, and to clarify how the piece could be used to measure the items.

The model similar to the tool used by Baryza had the following characteristics: $2 \mathrm{~mm}$ thick, $15 \mathrm{~cm}$ wide and $9 \mathrm{~cm}$ high made from acrylic material, laser cut, with rounded edges to avoid any damage to the evaluated scar, and labeled using an inkjet printer on clear vinyl adhesive paper, allocated $5 \mathrm{~mm}$ to the right edge and $4 \mathrm{~cm}$ from the left edge. The $5 \mathrm{~mm}$ space to the right of the plate was designed to allow evaluation of the maximum scar height, along with the plate thickness that gives another numerical parameter of height; and the $4 \mathrm{~cm}$ space on the left comprised the area where the scar would be compressed to free it from the influence of vascularization and to allow pigmentation assessment. In addition, a $9 \mathrm{~cm}$ long ruler was included to aid in measurements (Figure 2). Each participant of this stage was given a copy of this prototype, together with the evaluation documents.

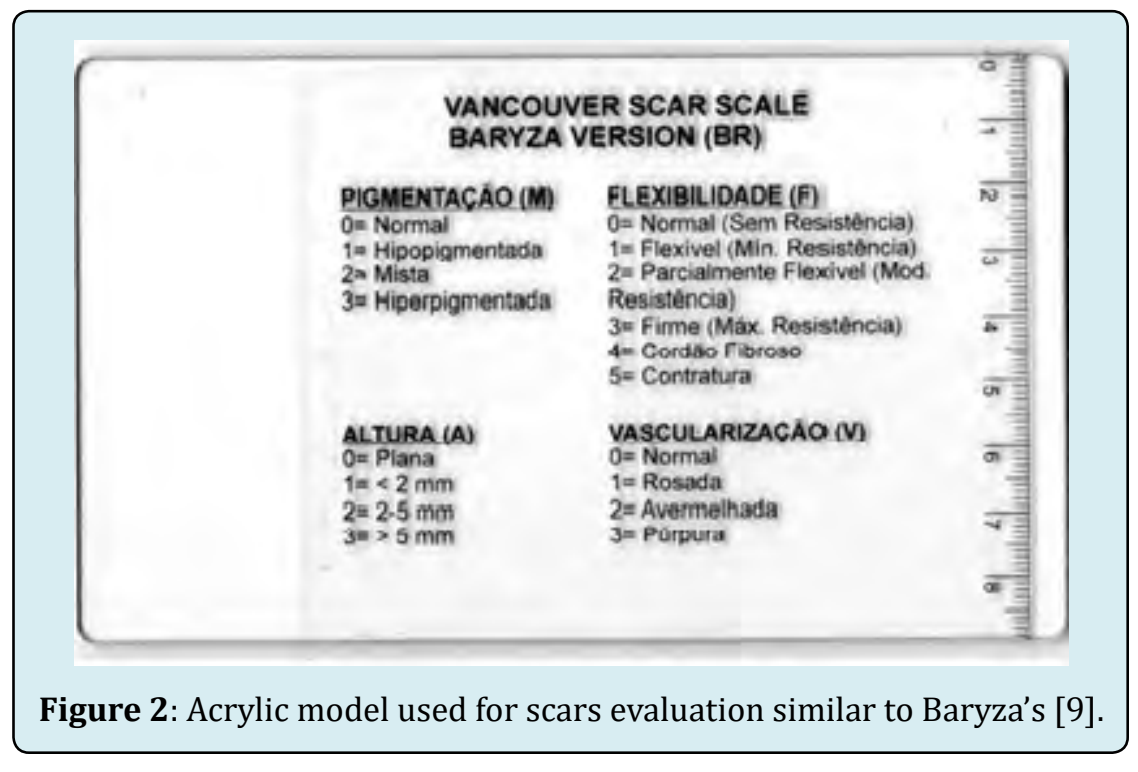

The study was approved by the Ethics and Research Committee on Human Beings of the Federal University of Santa Catarina, under number CAE 84783617.3.0000.0121, and observed the ethical-legal aspects in force in Brazilian legislation and resolutions of the Federal Nursing Council. All participants and researcher signed the Informed Consent Form, including. Authorization was given by the lead author of the instrument and the copyright holder of the publication.

It is should be highlighted that the analysis of this study was performed in a qualitative manner, based on the opinions and experiences of the participants in order to validate the steps. The result from the reports was the Vancouver Scar Scale - Baryza Version - Preliminary Version (VSS-BV-VP).

\section{Results}

During the first stage (translation of the scale into two versions of the Brazilian Portuguese language), the translators produced a written report highlighting terms that were difficult to translate so that it could be discussed in the summary of the two versions. Both reports as well as the translations and the original version were taken into consideration in the broad discussion in order to complete the next step, the summary of translations. Table 1 presents the following components for each set of evaluative items of the translated instrument: 1) the items of the original scale; 2) the items of the first translation (T1); 3) the items of the second translation (T2); and 4) the terms/items that were obtained by consensus among the members summoned for 
the translation summary stage (Table 1).

\begin{tabular}{|c|c|c|c|}
\hline VSS-BV & VSS-BV-T1 & VSS-BV-T2 & VSS-BV-T1-2 \\
\hline $\begin{array}{c}\text { Vancouver Scar Scale - } \\
\text { Baryza version }\end{array}$ & $\begin{array}{c}\text { Escala de cicatrização } \\
\text { Vancouver - Versão Baryza }\end{array}$ & $\begin{array}{c}\text { Escala de Cicatrização de } \\
\text { Vancouver - Versão Baryza }\end{array}$ & $\begin{array}{l}\text { Vancouver Scar Scale - } \\
\text { Baryza version (BR) }\end{array}$ \\
\hline Pigmentation (M) & Pigmentação (P) & Pigmentação & Pigmentação (M) \\
\hline 0 Normal & Normal & Normal & Normal \\
\hline 1 Hypopigmented & Hipopigmentada & Hipopigmentada & Hipopigmentada \\
\hline 2 Mixed & Mista & Mista & Mista \\
\hline 3 Hyperpigmented & Hiperpigmentada & Hiperpigmentada & Hiperpigmentada \\
\hline Vascularity (V) & Vascularização (V) & Vascularização & Vascularização (V) \\
\hline 0 Normal & Normal & Normal & Normal \\
\hline 1 Pink & Rosada & Rosada & Rosada \\
\hline 2 Red & Vermelha & Avermelhada & Avermelhada \\
\hline 3 Purple & Arroxeada & Púrpura & Púrpura \\
\hline Pliability (P) & Flexibilidade (F) & Flexibilidade & Flexibilidade (F) \\
\hline 0 Normal & Normal & Normal & Normal (sem resistência) \\
\hline 1 Supple (Min Res) & Flexível & Maleável (mínima resistência) & Flexível (mínima resistência) \\
\hline 2 Yielding (Mod Res) & Moderadamente flexível & $\begin{array}{l}\text { Suscetível à ruptura (moderada } \\
\text { resistência) }\end{array}$ & $\begin{array}{c}\text { Parcialmente flexível } \\
\text { (moderada resistência) }\end{array}$ \\
\hline 3 Firm & Firme & Firme & Firme \\
\hline 4 Ropes (Blanch) & Granular (esbranquiçada) & Pele esbranquiçada & $\begin{array}{l}\text { Cordão fibroso (máxima } \\
\text { resistência) }\end{array}$ \\
\hline 5 Contracture & Contraída & Contratura & Contratura \\
\hline Height (H) & Altura (A) & Espessura & Altura (A) \\
\hline 0 Flat & Rente & Plana & Plana \\
\hline $1<2 \mathrm{~mm}$ & & & \\
\hline $22-5 \mathrm{~mm}$ & & & \\
\hline $3>5 \mathrm{~mm}$ & & & \\
\hline
\end{tabular}

Note: VSS-BV - Vancouver Scar Scale - Baryza Version; VSS-BV-T1 - Vancouver Scar Scale - Baryza Version - Translation 1; VSSBV-T2 - Vancouver Scar Scale - Baryza Version - Translation 2; VSS-BV-T1-2 - Vancouver Scar Scale - Baryza Version - Translation $1-2$.

Table 1: Original, translated versions and summary of translations.

During the second stage (summary of translations) it was decided to keep the title in English identifying only the origin of cross-cultural adaptation (BR). The reason for this agreement was that it would facilitate access to this product in database searches and consequent use in international studies.

In the reports, the first translator had difficulties translating the English word "ropes", suggesting translation to "granular" and translator 2 reported difficulties translating the terms "yielding", "ropes" and "blanch", as he was unable to find a suitable technical translation. An agreement between the translations was not possible for the terms "Ropes (Blanch)", "granular - whitish" and "whitish skin" as they were not consistent with the care practice related to burns. Among the four members assigned to this stage (three researchers and the mediator), three had experience in the area of burn care.

In the set of items for the word "Pigmentation (M)" it was necessary to write instructions for scar assessment containing the concepts about the items and sub-items of the scale, in order to reduce the variety of interpretations. The initial "(M)" after the word "pigmentation" was kept in the 
consensus of translations because it is possibly related to the English word "melanin" which is similar to the same word in Portuguese, in addition to being different from the initial "(P)" for "pliability".

From the set of items "Vascularity (V)", we observed the tenuity between the concept of color tones observed in the scar ("pink", "reddish") and the possibility of using the word "erythema" instead of "reddish".

In the set "Pliability (P)", there was a doubt regarding the difference between elasticity and pliability. The idea of elaborating instructions for using the scale with terms corresponding to "fibrous cord", such as bridles and synechiae (for example, fibrous cord type) was reinforced; as well as the synonyms "malleable" and "flexible". Regarding the sub-item "partially flexible (moderate resistance)", the translation was also adjusted in order for it to be similar to the other sub-items. In this case, it was suggested to explain that the scar gives way under pressure; it is not considered a fibrous cord but has resistance. There were no comments or doubts regarding the set of items for "Height $(\mathrm{H})$ ".

In the third stage (expert committee assessment), the evaluation of the title, items and sub-items in relation to the objectivity, clarity and relevance of the scale components was of fundamental importance for transcultural equivalence, and where all decisions regarding semantic, idiomatic, experiential or cultural and conceptual equivalences were made. This step was outlined in Table 2 .

\begin{tabular}{|c|c|c|c|c|c|c|c|c|c|c|c|c|}
\hline \multirow{2}{*}{ Content } & \multicolumn{3}{|c|}{ Agree } & \multicolumn{3}{|c|}{ Partially agree } & \multicolumn{3}{|c|}{ Partially Disagree } & \multicolumn{3}{|c|}{ Disagree } \\
\hline & $\mathbf{0}$ & C & $\mathbf{R}$ & $\mathbf{0}$ & $\mathbf{C}$ & $\mathbf{R}$ & $\mathbf{0}$ & C & $\mathbf{R}$ & $\mathbf{0}$ & C & $\mathbf{R}$ \\
\hline Title & 3 & 1 & 2 & 1 & 2 & 2 & 1 & 2 & 1 & 0 & 0 & 0 \\
\hline Pigmentation (M) & 5 & 5 & 5 & 0 & 0 & 0 & 0 & 0 & 0 & 0 & 0 & 0 \\
\hline 0 Normal & 5 & 5 & 5 & 0 & 0 & 0 & 0 & 0 & 0 & 0 & 0 & 0 \\
\hline 1 Hypopigmented & 5 & 5 & 5 & 0 & 0 & 0 & 0 & 0 & 0 & 0 & 0 & 0 \\
\hline 2 Mixed & 5 & 5 & 5 & 0 & 0 & 0 & 0 & 0 & 0 & 0 & 0 & 0 \\
\hline 3 Hyperpigmented & 5 & 5 & 5 & 0 & 0 & 0 & 0 & 0 & 0 & 0 & 0 & 0 \\
\hline Vascularization (V) & 4 & 4 & 4 & 0 & 0 & 1 & 0 & 1 & 0 & 1 & 0 & 0 \\
\hline 0 Normal & 3 & 1 & 3 & 2 & 4 & 2 & 0 & 1 & 0 & 0 & 0 & 0 \\
\hline 1 Pink & 3 & 1 & 3 & 2 & 4 & 2 & 0 & 1 & 0 & 0 & 0 & 0 \\
\hline 2 Red & 3 & 1 & 3 & 2 & 4 & 2 & 0 & 1 & 0 & 0 & 0 & 0 \\
\hline 3 Purple & 3 & 1 & 3 & 2 & 4 & 2 & 0 & 1 & 0 & 0 & 0 & 0 \\
\hline Pliability (P) & 5 & 5 & 5 & 0 & 0 & 0 & 0 & 0 & 0 & 0 & 0 & 0 \\
\hline 0 Normal (No res) & 4 & 3 & 4 & 0 & 1 & 0 & 1 & 1 & 1 & 0 & 0 & 0 \\
\hline 1 Supple (Min res) & 4 & 3 & 4 & 0 & 1 & 0 & 1 & 1 & 1 & 0 & 0 & 0 \\
\hline 2 Yielding (mod res) & 4 & 3 & 4 & 0 & 1 & 0 & 1 & 1 & 1 & 0 & 0 & 0 \\
\hline 3 Firm & 4 & 3 & 4 & 0 & 1 & 0 & 1 & 1 & 1 & 0 & 0 & 0 \\
\hline 4 Ropes (max res) & 4 & 3 & 4 & 0 & 1 & 0 & 1 & 1 & 1 & 0 & 0 & 0 \\
\hline 5 Contrature & 4 & 3 & 4 & 0 & 1 & 0 & 1 & 1 & 1 & 0 & 0 & 0 \\
\hline Height(H) & 4 & 3 & 4 & 0 & 1 & 1 & 0 & 0 & 0 & 1 & 1 & 0 \\
\hline 0 Flat & 5 & 4 & 4 & 0 & 1 & 0 & 0 & 0 & 0 & 0 & 0 & 0 \\
\hline $1<2 \mathrm{~mm}$ & & & & & & & & & & & & \\
\hline $22-5 \mathrm{~mm}$ & & & & & & & & & & & & \\
\hline $3>5 \mathrm{~mm}$ & & & & & & & & & & & & \\
\hline
\end{tabular}

Note: O - Objective; C - Clarity; R - Relevance.

Table 2: Agreement on semantic, idiomatic, experiential and conceptual equivalences of the consensual translated version ( $\mathrm{n}=$ 5), according to number of evaluators. 
Regarding the title, one reviewer, who partially disagreed with the translation's purpose, clarity, and relevance, suggested that in order for the instrument to be better disseminated in Brazil, the title should be adapted as the translators suggested: "Vancouver Scare Scale - Baryza Version" but adding "- Brazil" to the end. However, after agreement from the majority of participants, the English title plus the acronym "BR" was kept, which refers to the country where the instrument was adapted (Brazil) (Table 2).

The five participants in the third stage agreed on the objectivity, clarity, and relevance of the item's translated terms and sub-items of "Pigmentation (M)" (Table 2).

Concerning the term "Vascularization (V)", one person disagreed with the objectivity of the translation, as they considered that "vascularization" is different from "vascularity". Partially agreeing with the purpose, clarity, and relevance of translating the "Vascularization" sub-items, one participant considered that the word / color "purple" is not usually used in our culture, and suggested switching to "purplish red" or maintaining the translations T1 and T2: "Purple / Purplish". Another evaluator partially agreed with the criteria of objectivity, clarity and relevance of these sub-items, justifying the preference for the word "purplish" because it is more used in practice than "purple". Another participant partially disagreed with the clarity aspect of the word "Purple", as they believed it is not related to the vascularization of the scar, but rather to spots and plaques, which could lead to confusion, suggesting only the term "purplish", resembling the word "Reddish" of subitem 2 (Table 2).

Regarding the "Pliability" sub-items, one evaluator partially disagreed with the objectivity, clarity and relevance, suggesting that the "Firm" and "Contracture" sub-items also contained explanations/qualifications, such as "Firm" - big or high resistance and "Contracture - Rigid" to resemble the "Normal - No resistance", "Pliable - Minimal resistance", "Partially pliable - Moderate resistance" and "Fibrous Cord Maximum resistance" sub-items (Table 2 ).

Regarding the item "Height", one evaluator disagreed with the objectivity and clarity of the term, judging that the thickness is as important, as or even more important than the assessment of scar height, suggesting it as another item (Table 2).
The set of produced documents was analyzed, and the procedure was recorded by means of a report containing all the questions and the clarification regarding all the decisions about the components of the VSS-BV. This report, as a consensus of the evaluations, reinforced the need to elaborate the VSS-BV (BR) instructions, especially regarding the clarification of differences or similarities between the terms: purple/purplish, height/thickness, maximum resistance/ rigid/fibrous cord/contracture. It was also agreed to add the explanation in parentheses "maximum resistance" to the subitem "Firm" and to exclude it in the subitem "Fibrous Cord" of the set "Pliability".

For the terms "pliability", "pliable" and "fibrous cord" a consultation with the original author and another expert in the field was suggested in order to detect different meanings in the translation. The suggestion to consult the original author came at a specific stage; the consultation with another burn specialist was accepted in the fifth step (summary of back translations). In addition, the mediator considered that "pliability" could also be correlated with "elasticity" (Table 2).

Regarding the fourth step (back translation in two versions), there was no consensus between back translations in relation to the word "vascularization". In the middle of the fifth step (summary of back translations), the mediator agreed with the term "Vascularization", stating that this term is used more in Brazil than "Vascularity", but it was suggested to consult a medical specialist in the vascular area to clarify if there is a difference between "vascularization" and "vascularity", as well as waiting for the next step regarding sending this proposal to the original author.

Thus, a vascular physician and a physiotherapist were consulted to confirm the terms. The vascular doctor confirmed the idea that in practice the most commonly used term is "vascularization" rather than "vascularity" and are not correlated to designate the presence of blood and/or lymphatic vessels. In turn, the physiotherapist, in addition to reiterating the previous idea, considered adding "without mobility or movement" to the explanation for "maximum resistance" of the subitem "Firm" in "Pliability".

Table 3 combines the steps regarding the versions of the construction of the back-translation summary step (fifth step) and shows the resulting version.

\begin{tabular}{|c|c|c|c|c|}
\hline VSS-BV & VSS-BV-VPF1 & VSS-BV-BT1 & VSS-BV-BT2 & VSS-BT-1-2 \\
\hline Pigmentation (M) & Pigmentação (M) & Pigmentation (M) & Pigmentation (M) & Pigmentation (M) \\
\hline 0 Normal & 0 Normal & 0 Normal & 0 Normal & 0 Normal \\
\hline
\end{tabular}




\begin{tabular}{|c|c|c|c|c|}
\hline 1 Hypopigmented & 1 Hipopigmentada & 1 Hypopigmented & 1 Hypopigmented & 1 Hypopigmented \\
\hline 2 Mixed & 2 Mista & 2 Mixed & 2 Mixed & 2 Mixed \\
\hline 3 Hyperpigmented & 3 Hiperpigmentada & 3 Hyperpigmented & 3 Hyperpigmented & 3 Hyperpigmented \\
\hline Pliability (P) & Flexibilidade $(\mathrm{F})$ & Flexibility (F) & Flexibility (F) & Flexibility $(\mathrm{F})$ \\
\hline 0 Normal & $\begin{array}{l}0 \text { Normal (sem resistên- } \\
\text { cia) }\end{array}$ & $\begin{array}{l}0 \text { Normal (without } \\
\text { resistance) }\end{array}$ & $\begin{array}{l}0 \text { Normal (without } \\
\text { resistance) }\end{array}$ & $\begin{array}{l}0 \text { Normal (without } \\
\text { resistance) }\end{array}$ \\
\hline 1 Supple (Min Res) & $\begin{array}{c}1 \text { Flexível (mínima resis- } \\
\text { tência) }\end{array}$ & $\begin{array}{l}1 \text { Flexible (minimal } \\
\text { resistance) }\end{array}$ & $\begin{array}{l}1 \text { Flexible (minimal } \\
\text { resistance) }\end{array}$ & $\begin{array}{l}1 \text { Flexible (minimal } \\
\text { resistance) }\end{array}$ \\
\hline 2 Yielding (Mod Res) & $\begin{array}{l}2 \text { Parcialmente flexível } \\
\text { (moderada resistência }\end{array}$ & $\begin{array}{l}2 \text { Partially flexible (mo- } \\
\text { derate resistance) }\end{array}$ & $\begin{array}{l}2 \text { Partially flexible (mo- } \\
\text { derate resistance) }\end{array}$ & $\begin{array}{l}2 \text { Partially flexible (mo- } \\
\text { derate resistance) }\end{array}$ \\
\hline 3 Firm & $\begin{array}{c}3 \text { Firme (máxima resis- } \\
\text { tência) }\end{array}$ & $\begin{array}{c}3 \text { Firm (maximal resis- } \\
\text { tance }\end{array}$ & $\begin{array}{c}3 \text { Firm (maximal resis- } \\
\text { tance }\end{array}$ & $\begin{array}{c}3 \text { Firm (maximal resis- } \\
\text { tance) }\end{array}$ \\
\hline 4 Ropes (Blanch) & 4 Cordão Fibroso & 4 Fibrous Cord & 4 Fibrous Cord & 4 Fibrous Cord \\
\hline 5 Contracture & 5 Contratura & 5 Contracture & $\begin{array}{c}5 \text { Contracture (contrac- } \\
\text { tion) }\end{array}$ & $\begin{array}{c}5 \text { Contracture (contrac- } \\
\text { tion) }\end{array}$ \\
\hline Vascularity (V) & Vascularização (V) & Vascularization (V) & Vascularization (V) & Vascularization (V) \\
\hline 0 Normal & 0 Normal & 0 Normal & 0 Normal & 0 Normal \\
\hline 1 Pink & 1 Rosada & 1 Pinkened/Pink & 1 Rosey/Pink & 1 Pink \\
\hline 2 Red & 2 Avermelhada & 2 Reddish & 2 Red & 2 Red \\
\hline 3 Purple & 3 Púrpura & 3 Purple & 3 Purplish/Purple & 3 Purple \\
\hline Height $(\mathrm{H})$ & Altura (A) & Height $(\mathrm{H})$ & Height $(\mathrm{A})$ & Height (A) \\
\hline 0 Flat & 0 Plana & 0 Flat & 0 Flat & 0 Flat \\
\hline $1<2 \mathrm{~mm}$ & & & & \\
\hline $22-5 \mathrm{~mm}$ & & & & \\
\hline $3>5 \mathrm{~mm}$ & & & & \\
\hline
\end{tabular}

Note: VSS-BV - Vancouver Scar Scale - Baryza Version; VSS-BV-VPF-1 - Vancouver Scar Scale - Baryza Version - Versão Pré-Final 1; VSS-BV-BT1 - Vancouver Scar Scale - Baryza Version - backtranslation 1; VSS-BV-BT2 - Vancouver Scar Scale - Baryza Version - backtranslation 2; VSS-BV-BT1-2 - Vancouver Scar Scale - Baryza Version - backtranslation 1-2.

Table 3: Consensus summary of back translations.

Regarding the sixth stage (comparison with the original version), the person responsible for the original version of the modified scale understood that the consensual version of the back-translations and the original scale were in agreement, indicating no alterations, changes of meaning or doubts, and therefore there was no need to resort to earlier stages.

In the seventh and last step (semantic validation), regarding the measurement prototype made from acrylic material (originally called Plexiglas ${ }^{\circledR}$ ), each of the four participants evaluated the instrument by applying it to people with burn scars. In this step, each practitioner completed the semantic validation sheets and then answered questions about understanding the items of the instrument and responses from the overall impression sheet. The invited reviewers had little or no experience on the subject.
In the item "Vascularization (V)", one evaluator highlighted the lack of clarity and consistency of the answers (sub-items) in relation to the items, reporting that the area of the "pleximeter" (the name used by the evaluators for the acrylic tool) is extensive, and made it difficult to assess the wound in some areas of scarring. Another evaluator found it difficult to understand the subheading "mixed pigmentation" referring to "Pigmentation (M)" and the "Reddish" and "Pinkish" subitems regarding "Vascularization (V)", asking that perhaps this last term was correlated with "hyperemia". The other evaluators did not have this same difficulty, nor did they find that the translated instrument was unclear.

Regarding the overall impression form, three of the four evaluators rated the overall scale as good and two rated it as very good. Regarding the items, three said that they 
were all were easy to understand, and one found that some items, such as "pigmentation and" vascularization" were difficult to understand. Regarding the response categories (sub-items), three reported that they had no difficulty using them and one evaluator found some difficulties regarding "hypopigmentation" and "hyperpigmentation". When asked about the relevance of the scale to the health/disease condition, the four evaluators indicated that it was very important.

Additionally, when asked what they would like to change in the instrument, they reported the following aspects: 1 ) the size of the "pleximeter", since the assessment area is large/wide, and causes problems for the vascularization assessment; 2) the order of the items for "Pigmentation (M)", "Vascularization (V)", "Pliability (P)" and Height (H) ", so that the first two items are assessed next, which would supposedly facilitate the differentiation; 3) differentiate "Pigmentation (M)" from "Vascularization (V)" with regard to the pressure of the acrylic; and 4) the scores of the subitems "Hypopigmented" and "Hyperpigmented" to be equal, since both bother the patient in the same way. When asked what they would add to the instrument, they indicated the addition of images to explain the items "Vascularization (V)" and "Pigmentation (M)".

Overall, the pre-final version reached a satisfactory level of equivalence, requiring neither the evaluation of translators, committee specialists and/or original scale author, nor any change related to the scale itself, without this being in violation of the objective and therefore resulting in the preliminary version of the instrument, which, in the next step, will be submitted to the pretest and analysis of the measurement properties.

\section{Discussion}

In order to evaluate and follow the evolution of scars longitudinally, subjective measures were introduced in clinical practice; and despite its lower accuracy in relation to objective measurements, its use in studies is advised because of its ability to achieve a more global assessment and to allow variable measurements that are not currently possible with objective equipment [22]. It should be noted that the accuracy aspect can also be improved by the preparation and knowledge of the professionals who give opinions based on subjective measurement scales.

Over the years, measurement scales have been modified into varying types and for different purposes, expanding to such an extent that it has made it more difficult to appropriately select and apply each case [23]. Thus, it is up to the professional interested in the application of an instrument to identify which one best portrays the reality in which it will be applied and if it meets the evaluation needs.

It is worth mentioning that cross-cultural adaptation has many advantages over the development of a new instrument, as it reduces costs and time, and allows for cross-cultural comparisons. In order for an instrument to be used in a new country, culture and/or language, it must be subjected to a unique method in order to achieve equivalence between source and target versions. The adaptation process involves the development of versions of an assessment instrument that are equivalent to the original but at the same time linguistically and culturally adjusted to a different context. Therefore, cultural, idiomatic, linguistic and contextual aspects concerning its translation must be considered [24].

Therefore, methodological rigor is required, including the researchers' uniformity, impersonality and obedience to the methodological proposal they intend to use, so that the values reflected by an instrument and the meanings of its components remain equivalent across cultures [25].

Regarding the most addressed issues in the methodological route, the set of terms of the item "Vascularization (V)" and "Pigmentation (M)", are highlighted, whose doubts persisted over many stages. There are restrictions in the literature regarding pigmentation and vascularization in the original version (VSS), meeting some emerging issues, such as the difficulty in assessing color (pigmentation and scar vascularization) [11].

The color of a scar, composed mainly of melanin and erythema, is an important factor in relation to aesthetics. Changes in vascularization (which relates to erythema) and pigmentation (which relates to melanin) may occur concomitantly, and scars are rarely homogeneous in color, making classification difficult and inaccurate for a human observer [22].

It is understood that the assessment of vascularization is an important scar parameter, since it is intrinsically associated with its maturation. During the healing process, the newly formed microvascular network and increased capillary blood flow meet increased metabolic demand and gradually decrease as the scar becomes mature. Thus, changes in vascularization are indicators of scar maturation [4].

As they are closely related to erythrocytes and red blood cells, which contribute to the redness of the skin color, most assessment instruments are based on the evaluation of scar redness in order to measure vascularization [4]. The measurement of erythema is influenced by patient-related factors such as activity and positioning of the affected areas, among other aspects, which compromise blood circulation 
and therefore skin erythema [22].

That said, the evaluator's limited knowledge or experience about aspects such as color can be confused, including assuming terms that would be synonymous but conceptually distinct.

In relation to the intended VSS-BV (BR), as with any other subjective scar assessment scale, it is difficult to differentiate the color of the scar from the naked eye which may be related to pigmentation or vascularization, such as differences between "Pinkish" and "reddish", "hypopigmented", "mixed pigmentation" and "hyperpigmented". In other words, the limitations regarding the terms related to vascularization are not exclusive to the VSS-BV-BR proposal, but rather to the subjective evaluation methods, which allow a classification relative to what is observed, since there is no way to accurately quantify color or its intensity, and is an action that is still hindered by the simultaneous nature of vascularization and pigmentation overlapping and changes [22].

Regarding the validation or semantic analysis step, in order to maintain the maximum resemblance to the original Baryza scale, and the agreement of the researchers, it was decided to maintain the order of the items (Pigmentation, Flexibility, Vascularization and Height) printed on the acrylic tool and in writing about the scale, as well as to disregard the change in the score of the subtypes Hypo and Hyperpigmented, in order to prevent any change, however subtle, from altering the meaning of the building.

Regarding the pleximeter, the objective of this crosscultural adaptation is to maintain the similarity between the translated and original scales, as well as the tool used for the scar assessment. Resizing the pleximeter could be the object of study for future validation, as it involves the assessment of change, i.e., the development of evidence for its justification.

Regarding the differentiation of pigmentation and vascularization with regard to pleximeter pressure, it is understood that the wording of the instructions, which seeks to provide knowledge, when using the scale, could be revised, as well as extra images to describe the responses of the vascularization and pigmentation items, which will be feasible on future occasion.

It is important to highlight that the original version of the VSS presents brief and generic instructions when conceptualizing the answers to the items. However, the research team understands the importance of its existing in the modified version, in order to standardize the assessment aspects among professionals who use the validated version. evaluators had no experience with the scar assessment, which may also have contributed to the many comments regarding the difficulties concerning the items and sub-items of "Vascularization (V)" and "Pigmentation (P)". This is seen as positive, since the objective is for the scale to be used by all professionals.

Although the results are related to the preliminary version, this study addresses the possibility of evaluating burn scars by means of a standardized instrument, regarding its appearance and severity.

\section{Conclusion}

The process of cross-cultural adaptation is strict but necessary to maintain equivalence between different cultures and languages. The process was carried out by proposing steps that remained true to their essence.

The resulting version, prior to semantic validation, did not require modification according to the original author of the scale. This pre-final version, when subjected to semantic validation, was considered by the evaluators as easy to understand, good and relevant to the health/disease issues related to burns, thus fulfilling the final purpose of this study.

It is believed that the final product of this research, after undergoing the pretest phase and subsequent analysis of its psychometric properties, may contribute to the improvement of the accuracy of the scale modified by Baryza and contribute to the availability of appropriate and valid instruments that can be applied to the Brazilian population with burns; providing easy and effective monitoring of the main characteristics of scars and corroborating the effort that has been made in standardizing evaluation measures.

The resulting version of this study shows adequate semantic validity and the instrument has an appropriate version to be pre-tested and evaluated for its psychometric properties, therefore, this is the preliminary Brazilian version of VSS-BV.

\section{Conflicts of Interest}

The authors declare no conflicts of interest.

\section{Funding}

This work was done during a scholarship funded by the Higher Education Personnel Improvement Coordination [Coordenação Aperfeiçoamento Pessoal do Nível SuperiorCAPES]. 


\section{References}

1. Brewin MP, Homer SJ (2018) The lived experience and quality of life with burn Scarring - The results from a large-scale online survey. Burns 44(7): 1801-1810.

2. Lv K, Xia Z, Chinese consensus panel on the prevention and treatment of scars (2018) Chinese expert consensus on clinical prevention and treatment of scar. Burns Trauma 6: 27.

3. Ai JW, Liu J, Pei SD, Liu Y, Li DS, et al. (2017) The effectiveness of pressure therapy $(15-25 \mathrm{mmHg}$ ) for hypertrophic burn scars: a systematic review and metaanalysis. Sci Rep 7: 40185.

4. Deng H, Li Tsang CWP (2019) Measurement of vascularity in the scar: a systematic review. Burns 45(6): 1253-1265.

5. Vercelli S, Ferriero G, Bravini E, Stissi V, Ciceri M, et al. (2017) Cross-cultural adaptation, reproducibility and validation of the Italian version of the Patient and Observer Scar Assessment Scale (POSAS). Int Wound J 14(6): 1262-1268.

6. Pham TD, Karlsson M, Andersson CM, Mirdell R, Sjoberg F (2017) Automated VSS-based burn scar assessment using combined texture and color features of digital images in error-correcting output coding. Sci Rep 7: 16744.

7. Clemons TDM, Bradshaw M, Toshniwal P, Chaudhari N, Stevenson AW, Lynch J, et al (2018) Coherency image analysis to quantify collagen architecture: implications in scar assessment. RSC Adv 8(18): 9661-9669.

8. Tyack Z, Simons M, Spinks A, Wasiak J (2012) A systematic review of the quality of burn scar rating scales for clinical and research use. Burns 38(1): 6-18.

9. Baryza MJ, Baryza GA (1995) The Vancouver Scar Scale: an administration tool and its interrater reliability. J Burn Care Rehabil 16(5): 535-538.

10. Gankande TU, Duke JM, Wood FM, Wallace HJ (2015) Interpretation of the DermaLab Combo ${ }^{\circledR}$ pigmentation and vascularity measurements in burn scar assessment: An exploratory analysis. Burns 41(6): 1176-1185.

11. Seyyah M, Yurdalan SU (2018) Cultural adaptation and validation of patient and observer scar assessment scale for turkish use. Burns 44(5): 1352-1356.

12. Mulay AM, Ahuja A, Ahuja RB (2015) Modification, cultural adaptation and validation of burn specific health scale-brief (BSHS-B) for Hindi speaking population.
Burns 41(7): 1543-1549.

13. Beaton D, Bombardier C, Guillemin F, Ferraz MB (2007) Recommendations for the cross-cultural adaptation of the DASH \& Quick DASH outcome measures. Institute for Work \& Health, Toronto, Canada.

14. Ferrer M, Alonso J, Prieto L, Plaza V, Monso E, et al. (1996) Validity and reliability of the St George's Respiratory Questionnaire after adaptation to a different language and culture: the Spanish example. Eur Respir J 9(6): 1160-1166.

15. Pasquali L (1999) Psychological instruments: practical elaboration manual. Brasília: LabPAM / IBAPP.

16. Dantas RAS (200\&) Cultural adaptation and validation of the Antonovsky Sense of Coherence Questionnaire in a sample of Brazilian cardiac patients. Thesis [Livre Teaching] - School of Nursing of Ribeirão Preto. Ribeirão Preto, São Paulo.

17. Echevarria Guanilo ME, Rossi LA, Dantas RAS, Santos CB (2006) Cross-cultural adaptation of the Burns Specific Pain Anxiety Scale-BSPAS to be used with Brazilian burned patients. Rev Latinoam Enferm 14(4): 526-533.

18. Ferreira E (2006) Cultural adaptation of the Burn Specific Health Scale-Revised-BSHS-R: version for Brazilians who suffered burns. Dissertation. Ribeirão Preto School of Nursing. Ribeirão Preto, São Paulo.

19. Freitas NO, Caltran MP, Dantas RAS, Rossi LA (2014) Translation and cross-cultural adaptation of the Perceived Stigmatization Questionnaire for burn victims in Brazil. Translation and cultural adaptation of the Perceived Stigmatization Questionnaire for burn victms in Brazil. Rev Esc Enferm USP 48(1): 25-33.

20. Freitas NO (2016) Cultural adaptation and validation of the Perceived Stigmatization Questionnaire (PSQ) and Social Comfort Questionnaire (SCQ) for Brazilians who suffered burns. Thesis. Ribeirão Preto School of Nursing / USP. Ribeirão Preto, São Paulo.

21. Fegadolli C (2008) Cross-cultural adaptation and validation of the DISABKIDS-37 instrument for Brazilian children and adolescents with chronic conditions: phase I. Thesis. Ribeirão Preto School of Nursing. Ribeirão Preto, São Paulo.

22. Lee SJ, Suh DH, Lee JM, Song KY, Ryu HJ (2016) Dermal Remodeling of Burn Scar by Fractional CO2 Laser. Aesthetic Plast Surg 40(5): 761-768.

23. Bae SH, Bae YC (2014) Analysis of Frequency of Use of Different Scar Assessment Scales Based on the Scar 
Condition and Treatment Method. Arch Plast Surg 41(2): 111-115.

24. Arafat SM, Chowdhury HR, Qusar S, Hafez MA (2016) Cross-cultural adaptation and psychometric validation of research instruments: A methodological review. J
Behav Health 5(3): 129-136.

25. Silva TON, Oliveira ILB, Balieiro MMFG, Mandetta MA, Tanner A, et al. (2015) Cross-cultural adaptation of an instrument to measure the family-centered care. Acta paul enferm 28(2): 107-112. 